\title{
Regimen Used to Treat Primary Malignant Neoplasm of Liver
}

National Cancer Institute

\section{Source}

National Cancer Institute. Regimen Used to Treat Primary Malignant Neoplasm of Liver. NCI Thesaurus. Code C67292.

Any regimen that can be used for the treatment of primary malignant neoplasm of liver. 